\title{
Geomagnetic Observations at the Equatorial East Coast of Brazil: importance, data and improvements of the Tatuoca Observatory
}

Gabriel Brando Soares* (ON), Jürgen Matzka (GFZ-Potsdam), Achim Morschhauser (GFZ-Potsdam), Katia Pinheiro (ON)

\section{Copyright 2016, SBGf - Sociedade Brasileira de Geofísica}

Este texto foi preparado para a apresentação no VII Simpósio Brasileiro de Geofísica, Ouro Preto, 25 a 27 de outubro de 2016. Seu conteúdo foi revisado pelo Comitê Técnico do VII SimBGf, mas não necessariamente representa a opinião da SBGf ou de seus associados. É proibida a reprodução total ou parcial deste material para propósitos comerciais sem prévia autorização da SBGf.

\section{Abstract}

The main goal of this work is to present recent data from the Tatuoca Magnetic Observatory (PA-Brazil) to demonstrate some exciting features of the geomagnetic field at the region, which make TTB a unique location to monitor the Earth's magnetic field. For example, the secular variation is very pronounced in this region, and the passing of the magnetic equator and the equatorial electrojet (EEJ) was recorded. In addition, it is also shown how Tatuoca Observatory was modernized in 2015, how it is working nowadays and which activities are being developed in relation to TTB data.

\section{Introduction}

The Magnetic Observatory of Tatuoca (TTB) is a unit of Observatório Nacional (ON). It was developed to measure continuously the magnetic field of the Earth, and is in operation since 1957. The observatory was installed at the small island of Tatuoca in the Amazon River, state of Pará, with coordinates $1.203^{\circ} \mathrm{S} 48.506^{\circ} \mathrm{W}$ (Figures 1 and 2).

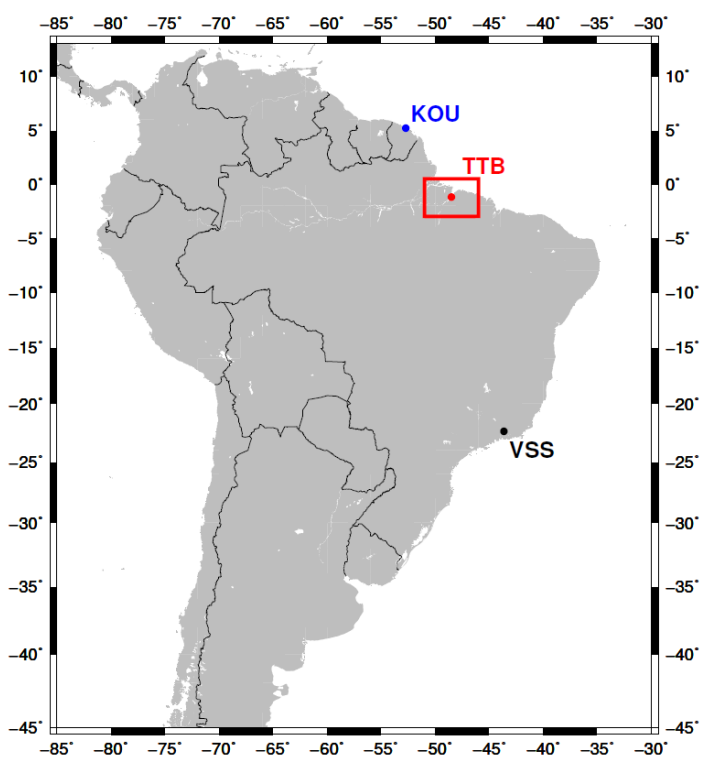

Figure 1: Location map with: Brazilian observatories VSS and TTB, and Kourou observatory (KOU) from French Guiana. In this work, data from TTB and KOU is used.
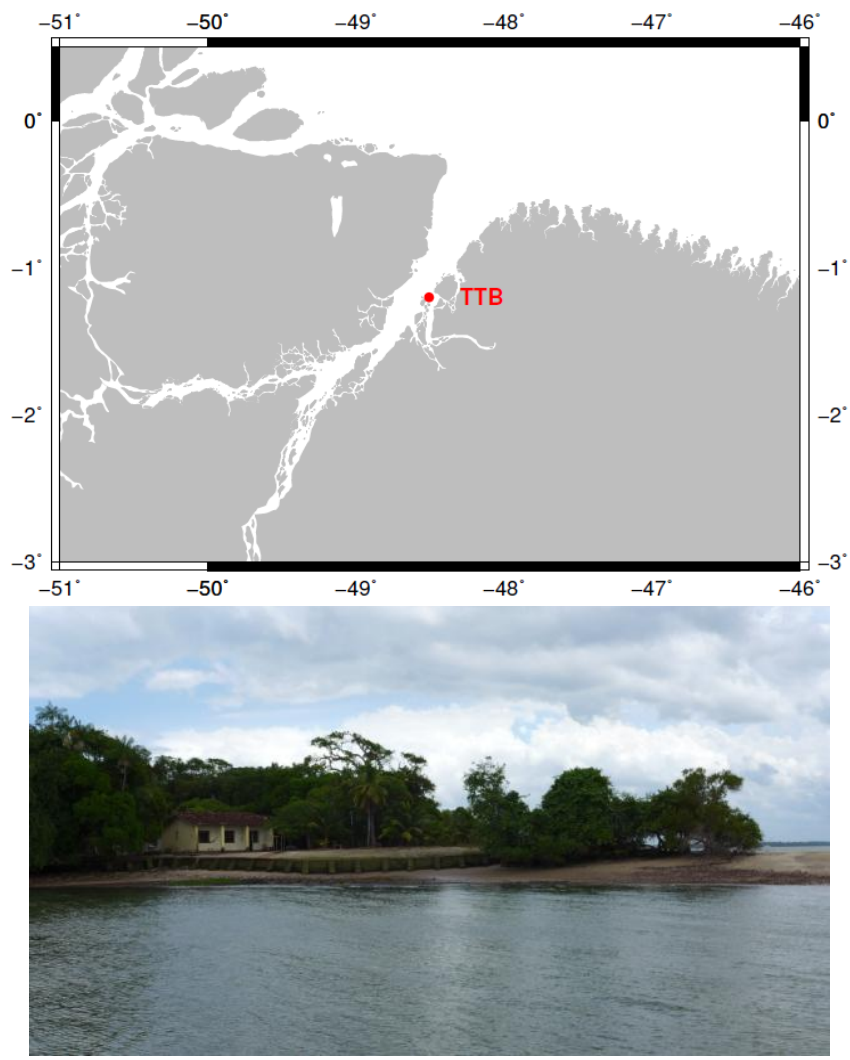

Figure 2:Top panel: Area in the red rectangle of Figure 1. Location of TTB (red dot) in the Amazon River, northern Brazil. Bottom panel: Photo of the observatory entrance (photo: Jürgen Matzka).

TTB was modernized in November 2015 through a cooperation between Observatório Nacional and the German Research Centre for Geosciences (GFZ). On this occasion, new equipment was installed, such as a new DTU FGE variometer with a low power data acquisition system and a new DTU model G fluxgate for absolute observations. Also, an internet system based on the mobile phone network was installed in order to provide near real time (NRT) data transfer.

The observatory is located close to the magnetic equator, in a region well suited both to obtain valuable data to better understand the geomagnetic field, and to allow scientific investigations of features like the Equatorial Electrojet (EEJ) and the South Atlantic Magnetic Anomaly (SAMA) (Figure 3).

The EEJ is an equatorial current system along the magnetic equator within a narrow band of about $2^{\circ}$ latitude. This current system is directed eastwards, 
leading to an enhancement of the horizontal component of the field at ground level, and moves with the sun from east to west on the upstream side / dayside. Further, this current system is caused by a special equatorial feature of the ionosphere's electrical conductivity: the medium can experience enhanced conductivity due to polarization of the ionosphere, caused by the Hall current. This polarization easily gets dissipated with the lines of force of the geomagnetic field, except in the region of the magnetic equator where the field is entirely horizontal, such as it is the case for TTB (Merril, 1996).

As visible in Figure 3 (top), where the global field intensity is shown, an area from South America to South Africa exists where the total field intensity is particularly low. This region is called South Atlantic Magnetic Anomaly (SAMA) and it currently drifts westward. TTB provides important data for long term variations of the field (secular variation) and core dynamics as it is placed at the SAMA region. Also, the observatory is located in an area with the globally strongest secular variation in $Z$ (nowadays it is $-180 \mathrm{nT} / \mathrm{yr}$, according to IGRF, Thebault et al., 2015).

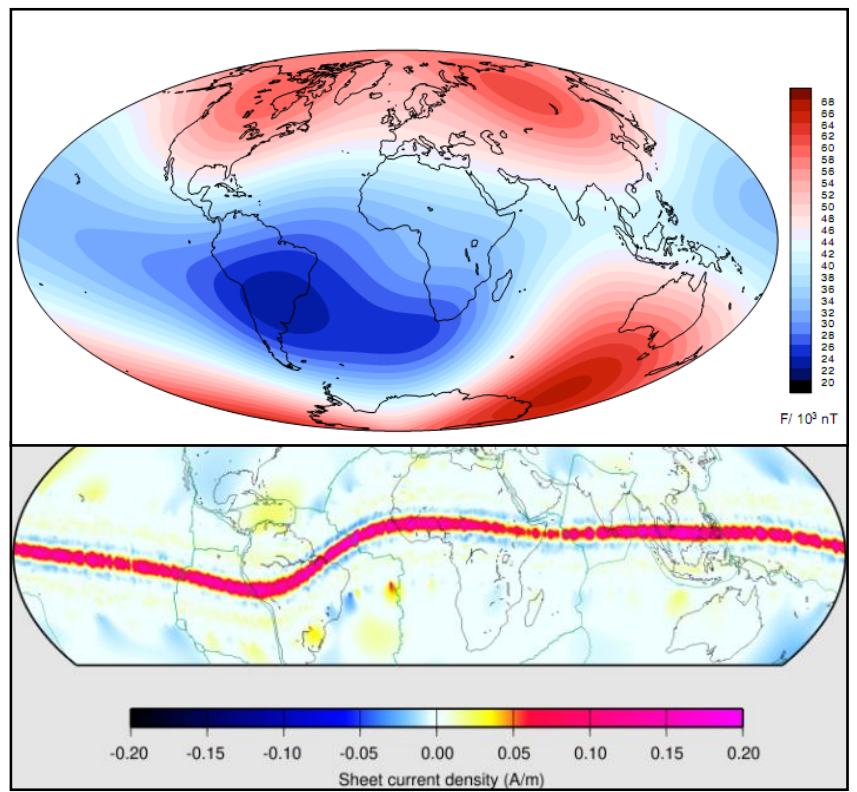

Figure 3: Top panel: the magnetic field at the Earth surface and the SAMA region. Bottom panel: the EEJ, an equatorial current system along the magnetic equator [ref.: http://geomag.org/info/equatorial_electrojet.html].

In this work we will use TTB data that we are currently calibrating back to 2008 to quantify the effects of EEJ and SAMA in ground-based measurements.

\section{Methodology}

Concerning the signal of the EEJ in TTB, we compared the daily variation of the $\mathrm{H}$ component of TTB to the one of KOU (Magnetic Observatory of Kourou, $5.210^{\circ} \mathrm{S}$ $52.731^{\circ} \mathrm{W}$, French Guiana). For this purpose, we chose a quiet period of $48 \mathrm{~h}$ on 21 and 22 of January 2011 by using the Dst-index (provided by WDC Kyoto). In this way, a plot of the $\mathrm{H}$-component of the field for TTB and KOU (versus time) allowed us to use a traditional method to calculate the effect of the EEJ as the difference between the geomagnetic components at two stations, with one of them directly at the magnetic equator (TTB). As a final result for this comparison, a second plot using just the difference $\mathrm{H} \mathrm{TTB}-\mathrm{H} \mathrm{KOU}$ was constructed. It is important to emphasize that an offset was subtracted from the $\mathrm{H}$-component values such that the quiet night time values are zero. Besides, the adopted time scale is decimal days, starting at 21 and ending at 23 .

Second, the secular variation of TTB Z component for the period of one year and the corresponding value predicted by the model CHAOS-6p (Finlay et al., 2016) for the region of TTB were compared. The KOU data was provided by INTERMAGNET.

For the analysis regarding the strong secular variation associated with the SAMA, we first used the DTU Magnetic Field Model CHAOS-6p (derived from Swarm, CHAMP and Orsted satellite magnetic data along with ground observatory data) to predict the field variation of the Z-component from 2008 until 2015 at the TTB location. In order to compare TTB observations with this model secular variation, we chose TTB daily means of the Z-component data for the entire year of 2011. Calibrated TTB data was loaded in INTERMAGNET software IMCDView and, then, the Z-component for the referred period of time was available.

\section{Results}

Regarding the EEJ, Figure 4 shows the intensity of the EEJ as the difference between TTB and KOU data during daytime. From this plot, the EEJ becomes discernible during daytime (beginning around $9 \mathrm{~h}$ local time). The difference between TTB peak and KOU peak (which can be considered an effect of EEJ) is around $85 \mathrm{nT}$ for both days. Here, we assume that the solar quiet $(\mathrm{Sq})$ current system at KOU is similar in strength as at TTB and that the entire difference is due to the EEJ.

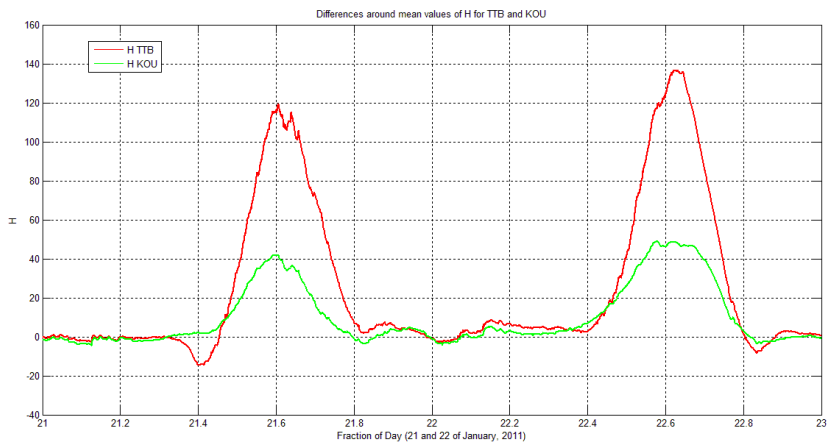

Figure 4: H-component values for TTB (red) and KOU (green) for the period of $48 \mathrm{~h}$ since midnight, January $21^{\mathrm{st}}$, 2011.

Hence, the difference in the core field of the observed magnetic field at these observatories was neglected, as 
our motivation is to study the EEJ which is considered a feature of the external field. Therefore, both plots were positioned at zero level and, compared to the disturbed daytime field, the nighttime field can be treated as a reference field of quiet period (representing the core field component).

Apart from the results found in Figure 4, a plot of the difference between H TTB and H KOU (Figure 5) reveals small negative peaks in the early morning and late afternoon hours. The first negative peak, around 21.4, has its origin in the so-called counter electrojet (CEJ), a reverse current system at the magnetic equator (Gurubaran, 2002).

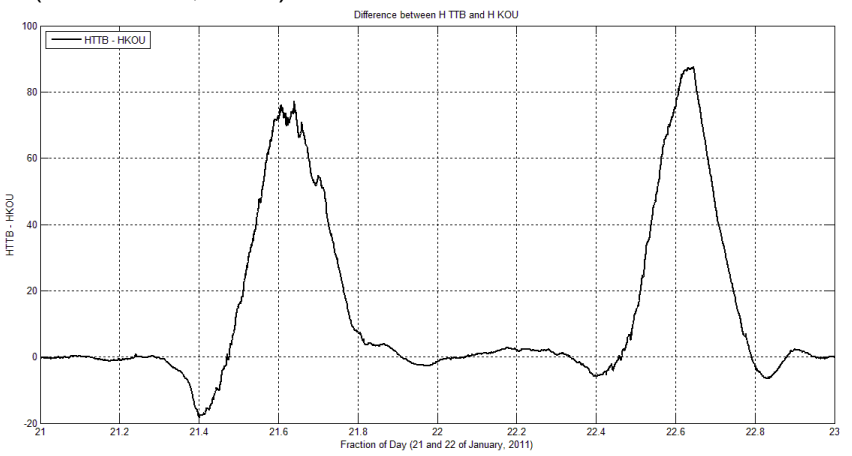

Figure 5: The H TTB - H KOU difference plot.

Another interesting feature of this comparison is that TTB and KOU curves are not always synchronized. Some delays can be observed regarding the exact timing of which curve is going up or down. For the chosen days, $\mathrm{H}$ KOU starts to increase before H TTB, both at 21.4 and 22.4 (daytime). Thus, the negative values found in Figure 5 can be a sum of these two presented small scale features.

The secular variation at TTB from a core field model and directly from observatory data is shown in Figures 6 and 7 , respectively. From Figure 7 , we extract the value of the long term variation of the Z-component at TTB, as follows: 232.7nT (at 31st December 2011) minus $443.8 \mathrm{nT}$ (at 1st January 2011), resulting in a variation of $-211.1 \mathrm{nT}$ per year. The obtained result fits nicely to the model prediction, which indicates a secular variation slightly exceeding -200 nT for 2011 (see Figure 6). The choice of the year of 2011 is justified by the fact that the secular variation is almost constant over the period of this year, allowing us to determine it from a linear fit to the data.

\section{Discussion and Conclusions}

The obtained results confirm the expected behavior for TTB data and demonstrate the value of its dataset.

Considering the study of the magnetic field of the Earth, it is interesting to note that TTB is a reliable source of data for researchers studying the main field or external field contributions, represented here by the cases of SAMA and EEJ, respectively. These exciting features fit well in the results obtained from the proposed comparisons in this work. Moreover, the results demonstrated that the CHAOS-6 model gave suitable results for our study.

As the geomagnetic field can have an important influence on human activities, for example by damaging highvoltage power transmission systems due to geomagnetically induced currents (GIC), by disturbing satellites operations, or by its use in oil industry research and production, the study about unique features that are still not entirely understood (like EEJ and SAMA) becomes a necessity. Investigations with TTB data could be used for this purpose.

In addition, TTB data can represent a regional reference magnetic field for the oil industry activities developed at the Brazilian Equatorial Margin, where the Foz do Amazonas and Pará-Maranhão Basins are located.

As the importance of TTB and its data is evident, our efforts to modernize the equipment and data transmission system of the observatory (producing better quality control of data) are justified. In this sense, we also calibrated the uncalibrated digital data record of TTB from 2008 until 2015.

\section{Acknowledgement}

We thank the staff and organizations operating Kourou Observatory and INTERMAGNET for providing data and the software to view and plot data.

\section{Refererences}

Merrill, R.T., McElhinny, M.W., McFadden, P.L., 1996. The Magnetic Field of the Earth. Academic Press Inc.

Hamid et al., 2014. Earth, Planets and Space, 66:146.

Venkatesh, K., P. R. Fagundes, D. S. V. V. D. Prasad, C. M. Denardini, A. J. de Abreu, R. de Jesus, and M. Gende, 2015. Day-today variability of equatorial electrojet and its role on the day-to-day characteristics of the equatorial ionization anomaly over the Indian and Brazilian sectors. J. Geophys. Res. Space Physics, 120, doi:10.1002/2015JA021307.

Hartmann, G.A., Pacca, I.G., 2009. Time evolution of the South Atlantic Magnetic Anomaly. Annals of the Brazilian Academy of Sciences, 81(2): 243-255.

Thébault et al., 2015. Earth Planets Space 67:79, doi:10.1186/s40623-015-0228-9.

Finlay, C.C., Olsen, N., Kotsiaros, S., Gillet, N. and Toeffner-Clausen, L., 2016. Recent geomagnetic secular variation from Swarm and ground observatories as estimated in the CHAOS-6 geomagnetic field model. [Submitted to Earth Planets and Space].

Gurubaran, S., 2002. The equatorial counter electrojet: Part of a worldwide current system? Geophysical 
Research Letters, Vol. 29, No. 9, 1337, 10.1029/2001GL014519, 2002.

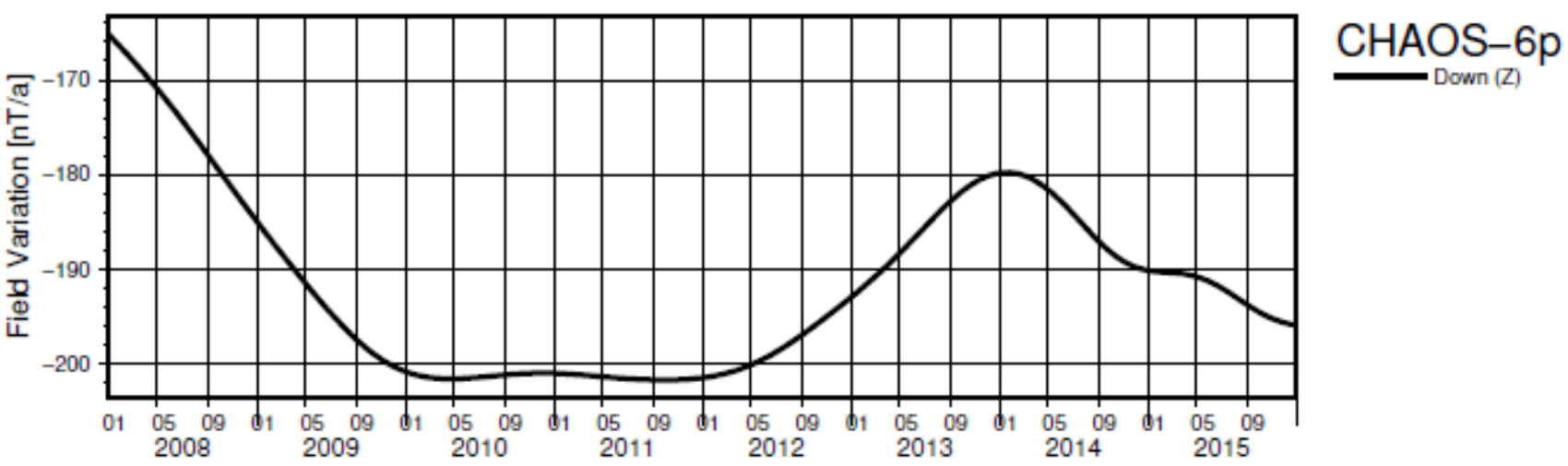

Figure 6: DTU Magnetic Field Model CHAOS-6 (derived from Swarm, CHAMP and Orsted satellite magnetic data along with ground observatory data) for Z-component variation from 2008 until 2015, at TTB location.

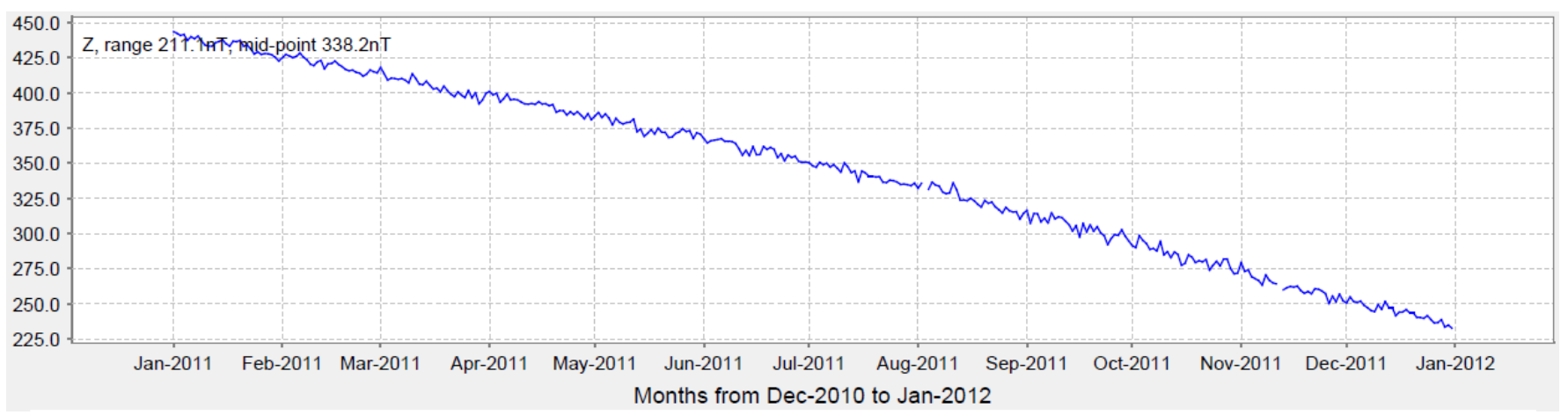

Figure 7: TTB Z-component data for the entire year of 2011. TTB data was loaded in INTERMAGNET IMCDView data viewer. 